\title{
SUBJECTIVE-PERSONAL READINESS OF CORRECTIONAL TEACHERS TO EDUCATION OF ASD CHILDREN
}

\author{
KATERYNA OSTROVSKA \\ Faculty of Pedagogy, Ivan Franko Lviv National University, \\ ul. Uniwersytetska, 1, Lwow, Ukraine \\ E-mail address: katerynaostrova@gmail.com
}

(c) $\underset{B Y}{(9)}$

\begin{abstract}
ASD teachers require skills that go beyond the realm of most educators including professional competences and high moral qualities.

In the work theoretical approaches and experimental research on the problem of subjective personality readiness of correctional teachers in the education of ASD children are carried out. The psychological investigation has been conducted including measurement of psychological indices of 40 teachers of ASD children from the boarding school "Trust" and 40 teachers from mainstream schools of Lviv city aged from 28 to 59 years. The following methods are used: "Questionnaire for the measurement of tolerance" (Magun, Zhamkochyan, Magura, 2000); "Shein's Career Anchors" method aimed at studying the career orientations of the teachers (Shein, 2010); "Diagnostics of empathy level" (Viktor Boiko, 2001); method of study "Motivation professional activities" by Catelin Zamfir in a modification of Artur Rean (Bordovskaya, \& Rean, 2001).

Based on the provided studies a program for development of subject-personality readiness of the correctional teacher to work with ASD children is proposed. The program consists of the following components: motivational component (professional competence, self-development, self-determination, self-control); cognitive component (intellectual personality autonomy, self-identification, stability, challenge, integration of lifestyles); emotionally-volitional component (empathy, positive attitude toward a child, intellectual analysis of emotions, self-regulation).

Key words: autism spectrum disorder (ASD) children, correction teachers, subject-personality readiness, motivational, cognitive, emotionally-volition components, professional activity.
\end{abstract}

\section{INTRODUCTION}

The job of a correctional teacher at the current stage of development receives a wide range of distribution and demands society support. Theoretical and methodological analysis of psychological and educational literature and research made it possible to assert that the subject-readiness of correction teachers for effective professional activity is not fully ensured. Therefore, there is a need 
to improve the subjective and personal readiness of correctional teachers for professional activities in this area.

Readiness to professional activity is a subjective state of the individual who knows himself or herself able and prepared for a particular activity due to labour education, vocational training, and mental training (Platonov, 1993). This subjective state includes various kinds of guidelines on awareness of task, model of probable behaviour, definition of social activity methods, assessment of capabilities in their relations with future challenges and the need to achieve a certain result (Slastenin, 1997). The components of readiness for pedagogical activity is professional self-awareness, attitude to work, motivation, knowledge of the subject and methods of work, skills and ability of practical implementation of these methods as well as professionally significant qualities of the person. The main characteristics of professional competence consists of the following components: understanding of the performed tasks; experience in this field and its active use; the ability to choose the means appropriate to specific tasks; responsibility for the achieved results; the ability to recognize mistakes and to make their correction (Khoruzha, 2008). A person estimating their own achievements and shortcomings, comparing them to the requirements of society and personal promising life goals, tends to self-improvement and to self-education, which makes him/ her a subject of his/her own professional activity (Kostyuk, 1998).

Thus, psychological requirements for professionals working with people with special educational needs include a system of motives, knowledge, skills, experience, personal qualities that ensure a successful professional career. Based on the overall structure of professional readiness, we believe that willingness of the correctional teacher to the profession in the field of special education should contain the following components: cognitive component (professional readiness for correctional work with autistic children, the formation of pedagogical competence); motivation (willingness as a collection of personality traits), emotional and volitional component (readiness is defined as the whole phenomenon of convictions, moral and volitional qualities of personality, behaviour, professional knowledge and practical abilities and skills), allowing correction teacher to take into account the individual characteristics of a child with autistic spectrum disorders in the educational activity. Readiness of correction teacher for professional work is considered by us as a complex of integrative formation of personality in which correctional educator is the bearer of personal qualities, which are important in working with ASD children - intrinsic motivation to activity, flexible thinking, self-improvement, empathy, tolerance, voluntary self-regulation, professional skills and knowledge of the individual characteristics of children.

ASD children struggle with communication and social interaction and demand a special approach to their education (Ostrovska, 2013). Thus, ASD teachers require skills that go beyond the realm of most educators. School social workers are often the professionals to first encounter and recognize the characteristics of autism spectrum behaviour (Dababnah et al., 2011). In addition, social workers should be comfortable identifying the early signs of 
autism spectrum disorders and using screening tools to determine if a child is at-risk for an autism spectrum disorder or other disorder (Dababnah et al., 2011). Teachers' attitudes toward the education/inclusion of ASD students have been widely studied (Rodriguez et al., 2012, Cassady, 2011). The above investigations showed mainly positive teachers' attitude to inclusive/special education of ASD students underlining the possible difficulties. Aleksandra Antonik presented a comprehensive analysis of various difficulties of ASD student education (Antonik, 2015). The analysis covers four areas whose characteristics can become a potential source of difficulties for ASD children teaching: 1) student characteristics related to autistic disorders, 2) characteristics of the school environment, 3) competence and professional preparation of teachers, 4) cooperation with parents and professionals working with the child (Antonik, 2015). Therefore, to overcome the above difficulties the teachers should be well skilled during university studies (Shulgenko, 2012, Shulgenko et al., 2014). The most attention should be paid to personal qualities of future teachers.

The aim of the current paper is to study the peculiarities of subjective personal readiness of correctional teachers for education of ASD children. For this purpose a comparison of personal characteristics of correctional teachers and teachers of mainstream school has been conducted.

\section{METHODOLOGY}

In the psychological study 80 teachers of secondary schools were involved. These were 40 teachers of ASD children from a boarding school "Trust" (30 women and 10 men) and 40 teachers from mainstream schools N53 and N65 of Lviv city ( 29 women and 11 men) aged from 28 to 59 years. The following methods were used:

1. "Shein's Career Anchors" - method aimed at studying the career orientations of teachers (Shein, 2010). The method reveals the following career orientations: professional competence, management, autonomy, stability, service, challenge, integration of lifestyles, enterprise. The total number of questions in the questionnaire - 41, of about 5 questions for every scale, which allows to determine the priority career orientation of correctional teachers.

2. "Questionnaire for the measurement of tolerance" (Magun, Zhamkochyan, Magura, 2000). The questionnaire included statements aimed at identifying the various kinds of tolerance: to representatives of other nations; to people from other places, to representatives of other cultures; tolerance to other views, including views and opinions of the minority; tolerance to deviations from generally accepted norms, rules and stereotypes; tolerance to complexity and uncertainty of the surrounding world. The questionnaire consists of 48 questions giving opportunity to estimate the general level of tolerance. Positive answer on $20 \%$ of questions evidences in low level of tolerance, $21-40 \%$ - lowered level of tolerance, $41-60 \%$ - average level of tolerance, $61-80 \%$ elevated level of tolerance, more $80 \%$ - high level of tolerance. 
3. The methodology "Diagnostics of empathy level" (Boiko, 2001). The questionnaire allows to determine the general level of empathy as well as various scale of empathy such as: rational channel of empathy; emotional channel of empathy; intuitive channel of empathy; installations that promote empathy; penetrating power in empathy; identification in empathy. The questionnaire consists of 36 questions. The scores for each scale can range from 0 to 6 points and indicate the significance of a particular parameter in the structure of empathy. The total score indicates in low (less than 14 points), lowered (15-22 points), average (23-29 points) and high (more than 30 points) level of empathy.

4. Methods of study "Motivation professional activities" by Catelin Zamfir in modification Artur Rean (Bordovskaya, \& Rean, 2001). The method is designed to diagnose motivation of correctional teacher on achievement of success in their correctional work with ASD children. The method consists in analysis of main motives of activity: 1) money earnings; 2) aspiration for advancement in work; 3) the desire to avoid criticism from the leader or colleagues; 4) the aspiration to avoid possible punishments or troubles; 5) the need to achieve social prestige and respect from others; 6) satisfaction from the process itself and the result of work; 7) the possibility of the most complete self-realization in professional activity. The method allows to establish the relationship between intrinsic and foreign motives of correctional teacher professional activities.

5. Methods of study of random self-control by German Nikiforov (Nikiforov, 1989). The technique is designed to diagnose the expression of self-control in emotional sphere, activity, behavior and includes the following scales: self-control in the emotional sphere, self-control in the activity, and social self-control, respectively. The questionnaire consists of 36 questions giving opportunity to estimate the general level of self-control. Positive answer on $20 \%$ of questions evidences in low, 21 - 40\% - lowered, $41-60 \%$ - average, 61 - $80 \%$ elevated, more $80 \%$ - high level of self-control. To analyze the results we used the following methods of mathematical processing: correlation analysis, comparative analysis (paired t-Student test) and carried out quantitative analysis of the results.

The main hypotheses:

1. We assume that most of correctional teachers will be exposed to a higher level of tolerance, service and empathy than teachers from mainstream schools.

2. We assume that correctional teachers have higher level of self-control, autonomy, challenge, pronounced focus on results than secondary school teachers.

\section{RESULTS AND DISCUSSION}

\section{Quantitative analysis}

According to the results obtained by the method of studying the career orientations ("Shein's Career Anchors") we found in $47.8 \%$ of secondary school teachers prevailing high level of professional competence, $31.3 \%$ - average, and $20.9 \%$ of teachers - low manifestation of the parameters. At 
the same time, the $62.4 \%$ of correctional educators demonstrate high level of professional competence, $21.6 \%$ of them - average and 16\% - low level. This indicates the correctional educators prevailing high level of professional competence, resulting in their quest to succeed in the professional sphere. As for relation to management, $38.3 \%$ of secondary school teachers showed prevailing high level of management, $33.5 \%$ - the average, and $28.2 \%$ - poor management, while the $45.6 \%$ correctional educators prevailing high level of management, $31.2 \%$ - the average, and $23.2 \%$ - the low level of manifestation of the parameters. Therefore, in correctional educators prevailing high level of career guidance management, resulting in the desire of the individual to achieve his career goals. As for relation to autonomy, the $64.5 \%$ correctional educators have a high level of autonomy, 18.1\% - average, and $17.1 \%$ - poor display of desire for autonomy. Instead, $37.6 \%$ of secondary school teachers set high manifestation of parameters, 33.2\% - average, and $29.2 \%$ - the low level of manifestation of the parameters. This indicates the correctional educators prevailing high level of desire for autonomy, characterized by the desire of the individual to free themselves from organizational rules, requirements and restrictions and a pronounced need to do everything on their own. All the above indicates that correctional teachers have more possibilities for enterprise, than secondary school teachers. The situation is generally connected with greater possibilities for development of correctional teacher skills because of current development of the correctional education in Ukraine as in scientific and practice dimension.

The above conclusions were confirmed by the further investigations of the teacher's relations to a challenge of society. Thus, $65.4 \%$ correctional educators have prevailing high level of challenge, $24.3 \%$ - average, and $10.3 \%$ - poor level of challenge, while only $41.2 \%$ of secondary school teachers call a high level, $30.5 \%$ - average, and $28.3 \%$ - the low level of manifestation of the parameters. This indicates the correctional educators prevailing high calling, which is characterized by the desire to overcome obstacles, solve complex problems, and make improvements in their activity.

The further investigations have shown that correctional teachers and teachers of mainstream school have the same level of stability in society. Thus, 55.6\% of secondary school teachers found a high level of stability, $25.3 \%$ - average, and $19.1 \%$ - low level of stability, while $58.7 \%$ of correctional educators set high stability, 28.6\% - average, and 12.7\% - low stability. In general, educators studied groups dominated by a high level of stability, expressed the desire for stable jobs. As for studies of lifestyle of the teachers, one can obtain the following results: $55.7 \%$ of secondary school teachers found a high level of integration styles of life, $25.6 \%$ - average, and $18.7 \%$ - the lowest level of manifestation of symptoms. Instead, the $53.5 \%$ correctional educators prevailing high level of integration styles of life, 28.2\% - average, and $18.3 \%$ - a low level of integration lifestyles. In the studied groups a high level of integration lifestyle dominates, which indicates of the wide outlook of teachers in general. 
Besides, it was established that $65.2 \%$ of correctional educators had a prevailing high level of service, $22.6 \%$ - average, and $12.2 \%$ - the lowest level of manifestation of the parameters, while only $52.4 \%$ of secondary school teachers have a high level of service, 30.2\% - average, and 17.4\% - low level of this trait. The correctional educators prevailing high level of service expressed the desire of the individual to work for others, which is connected with higher empathy.

The main results of the above investigations are shown in Figure 1.

Figure 1.

The results of teacher's studies according Shein's Career Anchors method.

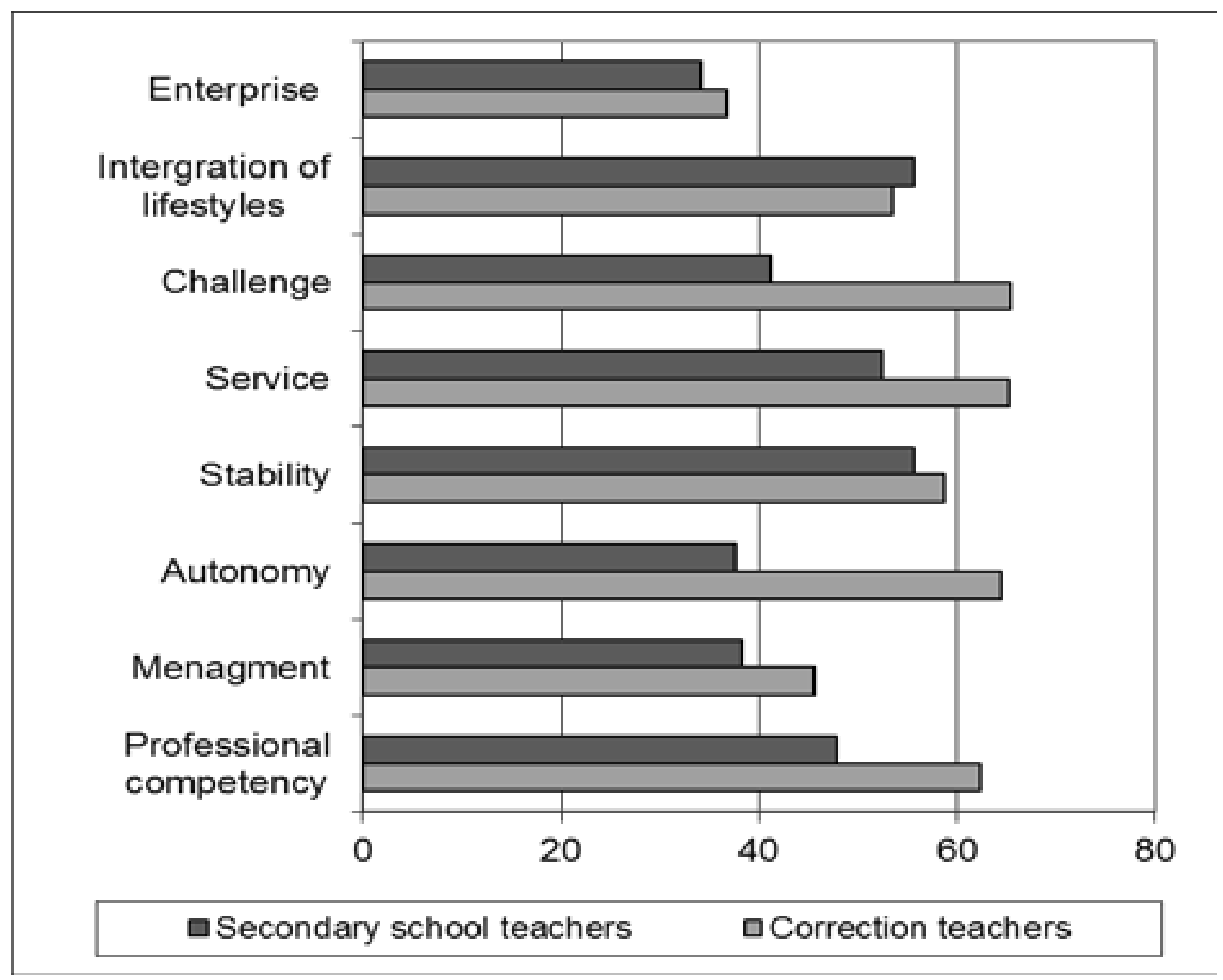

According to the results obtained by questionnaire to measure tolerance (Magun, Zhamkochyan, Magura, 2000) it was found that 49.5\% of secondary school teachers prevailing high level of tolerance, $34.2 \%$ - average, and $16.3 \%$ - a low level of tolerance. Instead, $66.7 \%$ of correctional educators have a high level of tolerance, in $26.4 \%$ - the average, and $6.9 \%$ - the lowest level of manifestation of symptoms. As correction teachers, unlike teachers of secondary school prevails a higher level of tolerance. Results of the above investigation are shown in Figure 2. 
Figure 2.

Results of teacher's studies by questionnaire of tolerance (by Magun, Zhamkochyan, Magura, 2000)

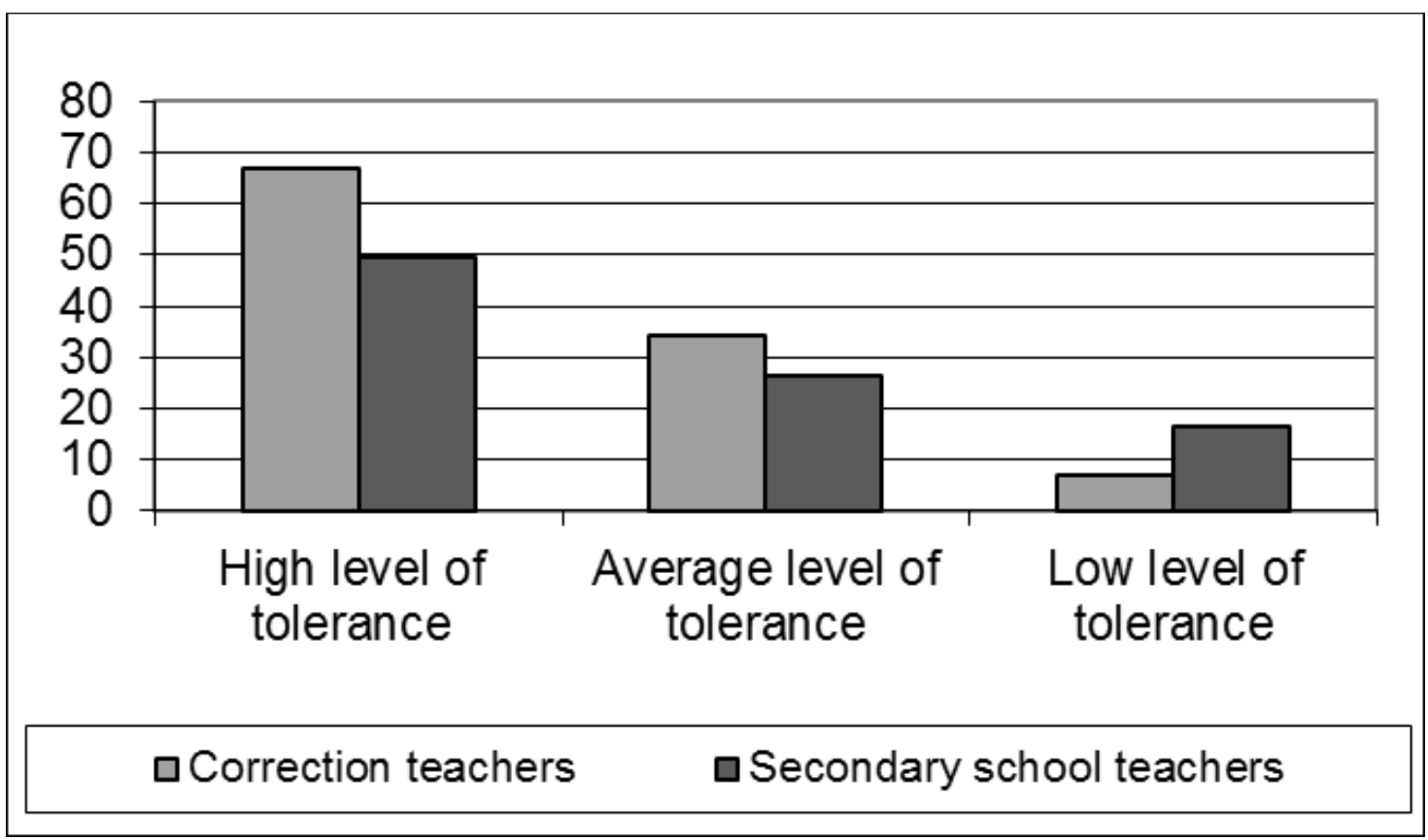

According to the results obtained by the method of empathy abilities study by Viktor Boyko it was found that in the majority of secondary school teachers prevails a rational channel of empathy, resulting in the ability of the teacher to create an atmosphere of openness, trust, intimacy. In correctional educators the predominant emotional and intuitive channels of empathy - the ability of the teacher to enter the emotional resonance with others - to empathize and to understand the inner world of another person.

\section{Correlative analysis}

Research of professionally important qualities of the structural components of subject-personal readiness for correctional teachers allowed us to highlight the correlation relationships. Correlation analysis of empirical data from a group of correctional educators allowed us to identify a number of significant relationships. The resulting direct correlation between indicators of sociability and empathy $(r=0,52)$ indicates in communication skills, ability to establish contacts associated with the ability of correction teacher for empathy. A direct correlation between indicators of sociability and self-motivation $(r=0,48)$ can be explained by the fact that the communication skills of the individual associated with the ability to manage their own emotions. A direct correlation between indicators of sociability, emotional and communicative motive $(r=0,49)$ indicates in the ability of the individual to establish contacts with other influences satisfaction of correctional teacher from his profession as a teacher, teaching work brings joy and satisfaction. The obtained direct correlation between indicators of sociability and self-motive $(r=0,44)$ could be explained by the fact that communication skills affect the feasibility of correctional teachers in their 
work because they have found themselves in this work, which can realize their creativity and help children to develop their interests and abilities.

The correspondent correlation relationships are shown in Figure 3.

\section{Figure 3.}

Relationships between empathy, ability to communication and various motives of correction teachers.

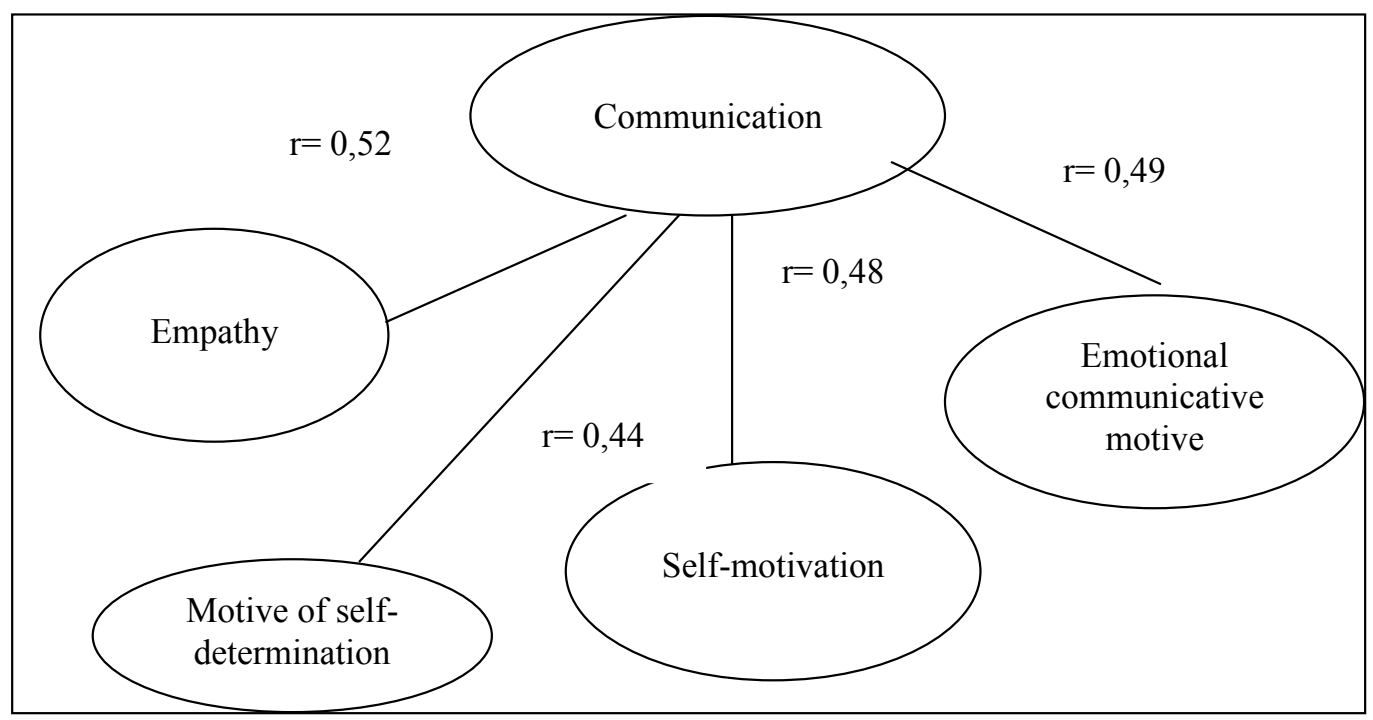

The established direct correlation between indicators of emotional awareness and propensity to self-control in the emotional sphere $(r=0,64)$ may explain the ability associated with emotional awareness of correctional teachers to control their emotions. They received a direct correlation between indicators of emotional empathy and propensity to self-control in the emotional sphere ( $\mathrm{r}$ $=0,85$ ) indicating a predisposition of the individual correctional educator for empathy associated with the ability to control their own emotional experience that plays an important role in work with children with autistic spectrum disorders. The correspondent correlation relationships are shown in Figure 4.

\section{Figure 4.}

Relationships between tendency to self-control and emotional awareness of correction teachers.

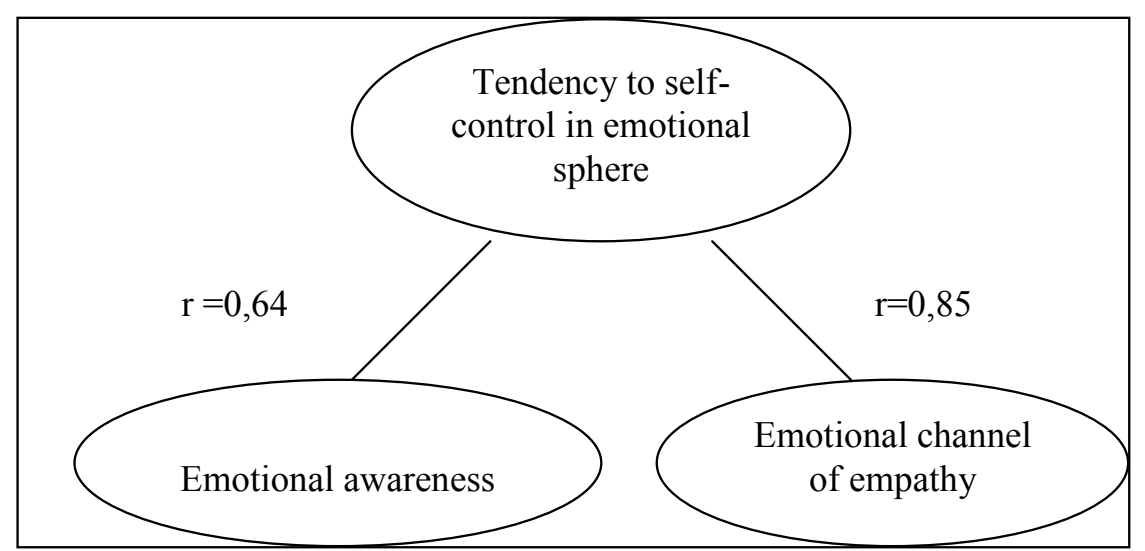


The established a direct correlation between the penetration rates in social empathy and self-control $(r=0,41)$ shows the ability of the individual to create a correctional teacher interaction with students in an atmosphere of openness, trust, shows the development in social self-identity, and the desire to act in accordance with social norms without breaking them. The correlation relationships are shown in Figure 5.

\section{Figure 5.}

Relationship between penetrating ability to empathy and social self-control of correction teachers.

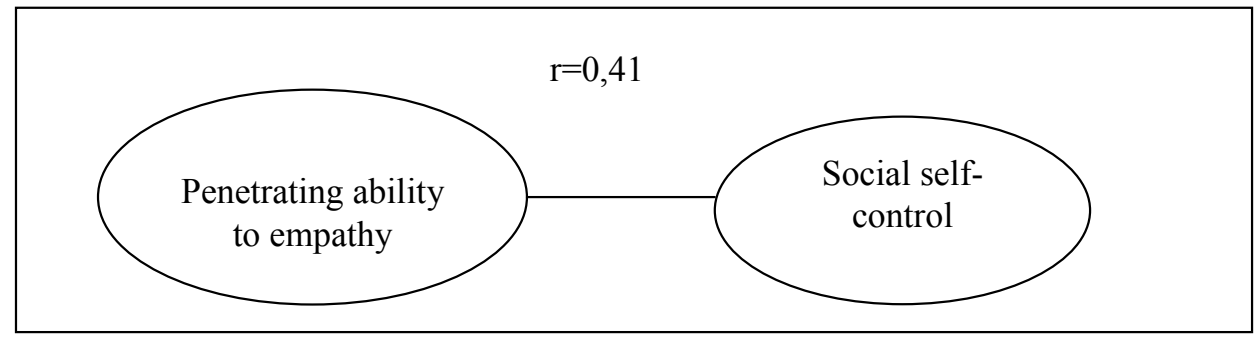

There is a direct correlation between indicators streamlined channel of empathy and tolerance $(r=0,53)$. This suggests that the ability of the individual correctional educator to comprehend another person is associated with high levels of tolerance. The resulting direct correlation between indicators focused on work and self-motivation $(r=0,42)$ evidences in the ability of the individual correctional educator to manage his/her emotions, to affect the activity including an increase in its effectiveness. A direct correlation between indicators focused on the work and ministry $(r=0,48)$ indicates the concentration of the individual in their own activities and a desire to perform work for the benefit of others.

\section{Figure 6.}

Relationship between intrinsic motivation, self-motivation and self-identification.

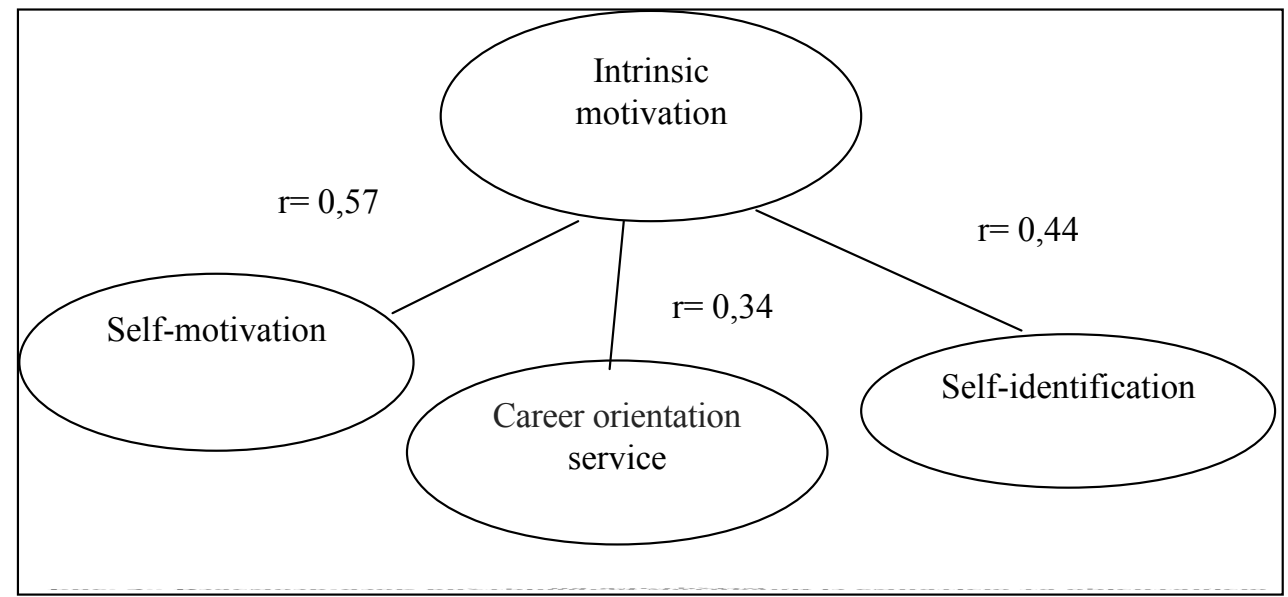

The established direct correlation between indicators of intrinsic motivation and self-motivation $(r=0,57)$ could be explained by the fact that the internal motivation of the individual correctional educator who works with children 
with autism is related to the ability to control their own emotional experience. The resulting direct correlation between indicators of internal motivation and self-identification $(\mathrm{r}=0,44)$ indicates that intrinsic motivation is in correlation with the ability to understand the other, setting yourself as a partner, intrinsic motivation the basis of successful personality identification of the other party, an important component of the subject-personal readiness of the correctional teacher to the education of children with autism. A direct correlation between indicators of intrinsic motivation and career orientation service $(r=0,34)$ shows that internal motivation is closely related to the human desire to work for the good of others. People of such orientation will not work in an organization that has goals and values that contradict its own, refuses to work and promote, if it fails to implement the core values of their life. The correspondent correlation relationships are shown in Figure 6.

\section{Comparative analysis}

An important part of the study was the diagnosis of psychological properties of correction teachers and secondary school teachers using comparative analysis according to Student $\mathrm{t}$-criteria. The studies allowed us to established the following results:

The difference in terms of emotional and communicative motive $(t=2,261$, $\mathrm{df}=47$, with $\mathrm{p}=0,0271$ ). A group of teachers of secondary school have a higher level of emotional and communicative motive as compared with group of correctional teachers. This suggests that pedagogical work brings greater joy and satisfaction to secondary school teachers than to correctional teachers because through communication secondary school teachers can observe the results of their work: positive changes and development of children, which get great satisfaction. Instead, correctional educators who work with students with autism cannot simply observe the results of their activities, they depend on the characteristics of the individual child, they need more time to see the progress of their own activities.

The established difference in terms of tolerance $(t=2,115$, $\mathrm{df}=47$, with $p=0,0346)$. Correctional teachers, unlike teachers of secondary schools, have higher levels of manifestation of this trait. This can be explained by the fact that correctional educators working with students with autism and should exercise tolerance in relation to them. Tolerance as the personal property of a teacher, is a precondition for successful work with students with special needs.

Thus, our first hypothesis is that the majority of correctional teachers will be exposed to a higher level of tolerance, service and empathy than teachers from mainstream schools, which is associated with a special need of ASD children fully confirmed, based on quantitative and comparative analysis.

In the two groups there is a difference between the level of autonomy $(t$ $=2,154, \mathrm{df}=47$, with $\mathrm{p}=0,0342$ ). In correctional teachers, unlike teachers of secondary schools, the higher levels of manifestation of this trait is observed. This indicates that correctional teachers, unlike teachers of secondary school, seeking independence in their own profession, freedom from institutional 
rules, requirements and restrictions as the teacher of children with autism require him or her to return to the psychological resources.

The difference in terms of challenge $(t=2,824$, $d f=47$, with $p=0,0075)$. Correctional teachers, unlike teachers of secondary school have higher level of manifestation of this trait. That indicates that correctional educators are seeking competition, overcoming obstacles, solving complex problems, improving professional activities, exploring new ways of working, because it contributes to their successful professional fulfillment.

The main results of the above discussion are shown in Figure 7.

Figure 7.

The results of comparative analysis of correctional and secondary school teachers.

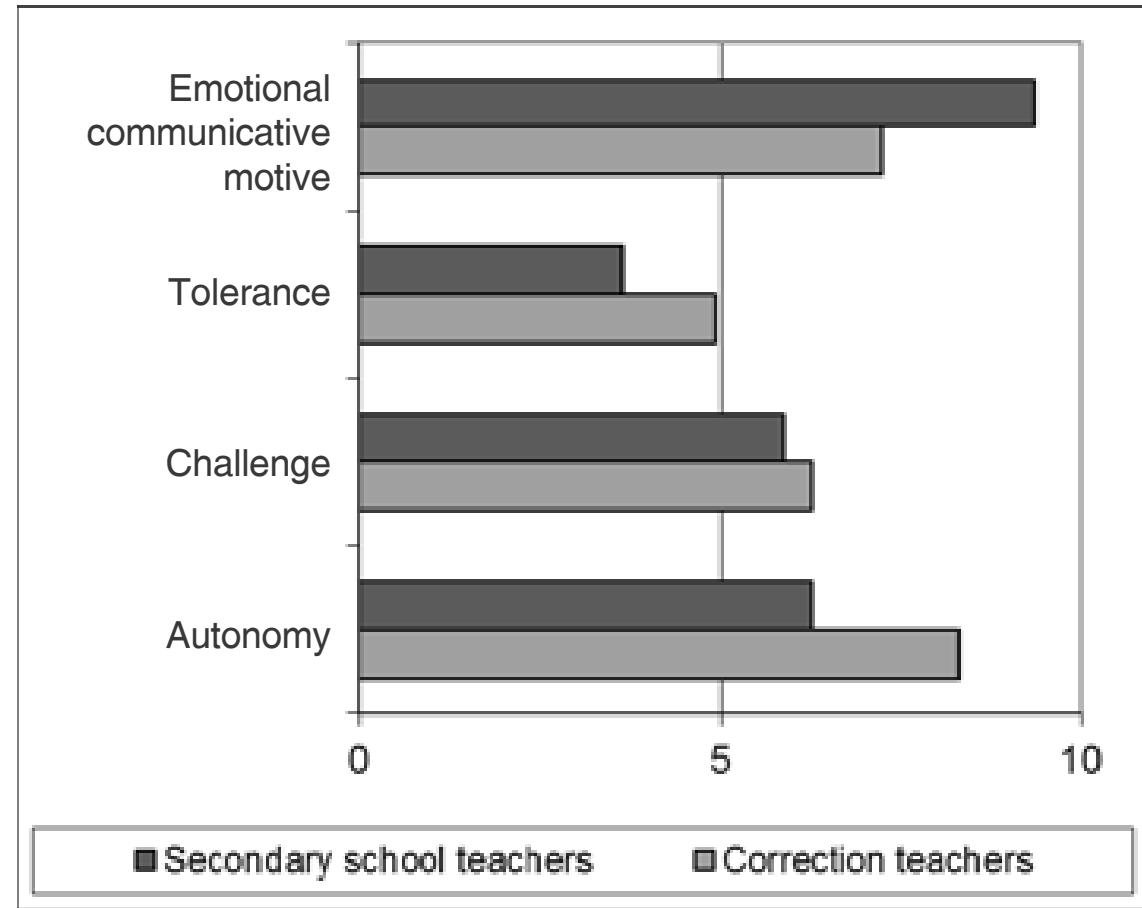

Thus, our second hypothesis that correctional teachers have higher level of autonomy, challenge, self-control, pronounced focus on results than secondary school teachers, is confirmed by a comparative ( $t$-Student test) and quantitative analyses.

Research of the subject-motivational component of personal readiness for correctional teachers leads to the conclusion that most of them are characterized by externally and internally deterministic performances and a higher level of development, regulation, control, self-development, self-control, autonomy, challenge, pronounced focus on results, altruism, the predominance of values, patience, responsibility than secondary school teachers. The study of the emotional and volitional component of subject-personal readiness to professional activity showed that correctional teachers have high levels of rational, emotional, intuitive channel and penetrating power of empathy in empathy, service, recognition of other emotions, emotional awareness, stress tolerance 
and middle level of self-motivation and emotional and communicative motive. The study of cognitive component of subjective-personal readiness showed that correctional teachers have high levels of personal intellectual autonomy, self-identification resulting in integration challenge and lifestyles.

\section{CONCLUSIONS}

Subjective readiness of acorrectional teacher to the profession is a complex integrative formation of personality in which a correctional educator becomes the bearer of personal qualities, especially those that are important in working with ASD children - intrinsic motivation, flexible thinking, self-improvement, empathy, tolerance, voluntary self-regulation, professional skills and knowledge of the individual characteristics of children. Correctional teachers have higher levels of tolerance, challenge, autonomy and lower emotional and communicative motives as compared with secondary school teachers. Secondary school teachers have a higher level of emotional and communicative motive and lower tolerance, call and autonomy.

Taking the results of the above investigation into account one can propose a program for development of subjective readiness of correctional teacher to the education of ASD children which includes motivational component (professional competence, self-development, self-determination, self-control); cognitive component (intellectual personality autonomy, self-identification, stability, challenge, integration of lifestyles); emotionally-volitional component (empathy, positive attitude toward a child, intellectual analysis of emotions, self-regulation).

\section{REFERENCES}

[1] Antonik, A. (2015) Nauczyciel wobec trudności związanych z edukacją uczniów z zaburzeniami ze spektrum autyzmu w warunkach szkoły integracyjnej i ogólnodostępnej. Analiza obszarów problemowych [Teachers Faced with Difficulties of Educating Students with Autism Spectrum Disorders in Integration and Mainstream Schools. An Analysis of Problem Areas]. Studia Edukacyjne 34, 153-165.

[2] Bojko, V.V. (2001) Диагностика уровня эмпатических способностей / Практическая психодиагностика. Методики и тесты [Diagnotics of empathy ability level / Practical psychodiagnotics. Methods and tests] Samara: Бaxpax-M.

[3] Bordovskaya, N.V., \& Rean, А.А. (2001) Педагогика [Pedagogics], St. Petersburg: Питер.

[4] Cassady, J. M. (2011). Teachers' Attitudes Toward the Inclusion of Students with Autism and Emotional Behavioral Disorder. Electronic Journal for Inclusive Education, 2 (7), 1-23. Retrieved from http://corescholar.libraries.wright.edu/cgi/viewcontent. cgi?article $=1127 \&$ context $=$ ejie

[5] Dababnah, S., Parish, S.L., Brown, L.T., \& Hooper, S. R. (2011). Early screening for autism spectrum disorders: A primer for social work practice. Children and Youth Service Review, 33, 265-273.

[6] Khoruzha, L.L. (2008) Деонтологічні основи педагогічної професії [Deontologic base for pedagogical activity]. Kyiv: КМПУ ім. Б.Д.Грінченка.

[7] Kostyuk, G.S. (1998) Избранные психологические труды [Selected psychological works]. Moscov: Педагогика. 
[8] Magun, V.S., Zhamkochyan, M. S., \& Magura, M. (2000). Оценка эффективности тренинга толерантности как средства воздействия на сознание старшеклассников. На пути к толерантному сознанию [Evaluating the effectiveness of the training of tolerance as a means of influencing the minds of high school students. On the way to an attitude of tolerance]. Moscov: Смысл.

[9] Nikiforov, G.S. (1989). Самоконтроль человека [Human self-control]. St.Petersburg: Издательство Ленинградского университета.

[10] Ostrovska, K.O. (2013). Peculiarities of social competence in children with different autistic levels. Journal of Education, Culture and Society, 1, 133-147.

[11] Platonov, K.К. (1993) Структура и развитие личности [Structure and development of personality]. Moscov: Наука.

[12] Rodriguez, I., Saldana, D., \& Moreno, J. (2012). Support, inclusion and special education. Teachers' attitudes toward the education of students with autism spectrum disorders. Autism Research and Treatment, 1. doi:10.1155/2012/259468

[13] Schein, E. H. (2010). Organizational culture and leadership (Vol. 2). John Wiley \& Sons.

[14] Shulgenko, A., \& Ostrovskii, I. (2014). University studies of future psychologists to work with autistic children. Journal of Education, Culture and Society, 1, 87-96.

[15] Shulgenko, D.I. (2012) Професійна готовність студентів до корекційної роботи 3 аутичними дітьми [Professional readiness of students to correction work with ASD children]. Proceedings of Kamenetz-Podolsk National University named after Ivan Ogijenko, 21(2), 391-399. Retrieved from http:/ / nbuv.gov.ua/UJRN/znpkp_sp_2012_21(2)_55

[16] Slastenin, V.A. (1997) Педагогика - инновационная деятельность [Pedagogics - innovative activity]. Moscov: Магистр. 